\title{
One Year of Family Physicians' Observations on Working with Medical Scribes
}

\author{
Amelia Sattler, MD, Tracy Rydel, MD, Cathina Nguyen, RN, MPH, and \\ Steven Lin, MD
}

Purpose: The immense clerical burden felt by physicians is one of the leading causes of burnout. Scribes are increasingly being used to help alleviate this burden, yet few published studies investigate how scribes affect physicians' daily work, attitudes and behaviors, and relationships with patients and the workplace.

Methods: Using a longitudinal observational design, data were collected, over 1 year, from 4 physicians working with 2 scribes at a single academic family medicine practice. Physician experience was measured by open-ended written reflections requested after each 4-hour clinic session. A data-driven codebook was generated using a constant comparative method with grounded theory approach.

Results: A total of 361 physician reflections were completed, yielding 150 distinct excerpts; 289 codes were assigned. The 11 themes that emerged were further categorized under 4 domains. The most frequently recurring domain was clinic operations, which comprised $51.6 \%$ of the codes. Joy of practice, quality of care, and patient experience comprised $22.1 \%, 16.3 \%$, and $10.0 \%$ of the codes, respectively.

Conclusions: Our study suggests that integrating scribes into a primary care clinic can produce positive outcomes that go beyond reducing clerical burden for physicians. Scribes may benefit patient experience, quality of care, clinic operations, and joy of practice. (J Am Board Fam Med 2018;31:49-56.)

Keywords: Family Physicians, Grounded Theory, Primary Health Care, Professional Burnout, Quality of Health Care

Burnout among US physicians is a serious and growing problem with profound implications for society. ${ }^{1}$ More than half of all US physicians are experiencing professional burnout, and family physicians have one of the highest rates of burnout among the specialties. ${ }^{2}$ A major contributor to burnout among physicians is growing workload outside of the examination room. ${ }^{3-5}$ For every hour physicians spent in direct contact with patients, 2 more hours are spent on electronic health record (EHR) and desk work. ${ }^{6}$ Many physicians document only brief notes during a clinic visit, leaving most of

This article was externally peer reviewed.

Submitted 21 July 2017; revised 19 September 2017; accepted 23 September 2017.

From the Division of Primary Care and Population Health, Department of Medicine, Stanford University School of Medicine, Stanford, CA.

Funding: This study was supported by a grant to S.L. from the Pisacano Leadership Foundation, the philanthropic foundation of the American Board of Family Medicine.

Conflict of interest: none declared.

Corresponding author: Steven Lin, MD, 211 Quarry Road, Suite 405, MC 5985, Palo Alto, CA 94304 (E-mail: stevenlin@stanford.edu). the charting to the end of the day and spending 1 to 2 hours each night working on the EHR. ${ }^{6}$

To decrease the clerical burden felt by physicians, many US hospitals and clinics have adopted the use of scribes. ${ }^{7}$ Scribes are nonlicensed individuals trained to document patient encounters in real time under the direct supervision of a physician. ${ }^{8}$ Scribes assist with charting, recording laboratory and radiology results, and supporting physician workflow with EHR data entry. ${ }^{8}$ The popularity of scribes in the United States has risen sharply recently, and at least 22 companies are recruiting, training, and providing scribes to physicians. ${ }^{7}$ The number of scribes has been doubling annually; it is estimated that by 2020 , there will be 100,000 scribes in the United States, or 1 scribe for every 9 physicians. $^{7}$

Despite the rapid uptake of scribes in US hospitals and clinics, little is known about how scribes affect the daily work of physicians, how they fit into the dynamic interactions between physicians and patients, and how they change relationships and team structures in established practices. Existing 
studies of scribes are few and offer very limited qualitative data. ${ }^{9,10}$ Few studies have explored the perspectives of physicians, scribes, and patients regarding scribes in primary care. ${ }^{11,12}$

To our knowledge, no longitudinal observational study of scribes has examined their impact on physicians' daily work, attitudes and behaviors, and relationships with patients and the workplace. Our aim was to explore these questions through an ethnographic study of physicians and scribes in an academic family medicine clinic, using repeated observations and data collection over 1 year. Our objective was to identify challenges and opportunities resulting from physicians and scribes working together as they relate to patient experience, quality of care, clinic operations, and joy of practice.

\section{Methods \\ Design}

The study was conducted from July 1, 2015, to June 30,2016 , at a single family medicine clinic associated with an academic medical center in California. Four physicians and 2 scribes participated in the study. All physicians were board certified in family medicine, with a mean of 6 years of experience; none had prior experience with scribes. All 4 physicians were faculty clinician-educators with a clinical full-time equivalent ranging from 0.5 to 0.75 . Both scribes held baccalaureate degrees and completed an 80 -hour training course administered by a commercial company (Elite Medical Scribes, Bloomington, $\mathrm{MN}$ ).

The qualitative data used in this research were collected as part of a larger randomized controlled study of scribes, described elsewhere in the literature. ${ }^{13}$ Physicians were assigned a schedule of 1 week practicing with a scribe alternating with 1 week without a scribe. During the weeks when the physician was assigned a scribe, the scribe attended all patient encounters alongside the physician and drafted all relevant documentation, including the patient history, objective examination findings, assessment and plan, and patient instructions. The physician was required to review all scribed notes for accuracy before signing/closing the chart. During the weeks when the physician was not assigned a scribe, the physician was responsible for all charting. The outpatient version of the Epic EHR (Epic Systems Corp., Verona, WI) was used.

\section{Survey}

Physician experience was measured by a self-administered questionnaire that included a free response section in which they were asked to record observations about their clinic experience. Physicians were offered 1 questionnaire after each 4-hour clinic session throughout the 1-year study period. This approach allowed physicians to record "just-in-time" observations akin to keeping a diary, following the principles of ethnography. ${ }^{14}$ Entries had no word limit restrictions and could be completed any time after each 4-hour clinic session. If an entry was left blank after a week, an automatic reminder was sent to the physician, inviting him or her to complete it.

\section{Coding}

A codebook was developed using a constant comparative method with the grounded theory approach. ${ }^{15}$ Three reviewers (AS, TR, SL) identified and defined the recurring themes from the surveys using a data-driven methodology, with triangulation from the literature. The codebook was iteratively refined until the final themes were unanimously agreed on (Table 1).

All physician entries were transcribed into Dedoose (version 7.0.23), a web-based qualitative data analysis software. Using Dedoose, 2 coders (CN, $\mathrm{SL}$ ) independently reviewed each survey and identified the relevant excerpts, labeling each comment with $\geq 1$ code according to the codebook. The content units for data analysis were words and phrases. Interrater agreement was analyzed. The coded units were then grouped based on categorical themes/domains. The coders were blinded to the authors of the entries.

\section{Institutional Review Board Approval}

This study was exempted from formal review by the institutional review board of the Stanford University School of Medicine.

\section{Results}

Over the study period, a total of 361 physician reflections were completed, yielding 150 distinct excerpts with 289 code assignments. Physicians completed $73 \%$ (361 of 494) of the surveys offered. Two physicians contributed equally to $88 \%$ (316 of 361 ) of the completed surveys; the other 2 physicians returned $12 \%$ (45 of 361). Eleven recurring 
Table 1. Codebook Developed for Qualitative Data Analysis

\begin{tabular}{lc}
\hline Codes & Description \\
\hline Teamwork/partnership & Physician refers to impact of teamwork or partnership, including (but not limited to) \\
team-based care and joy of teaching; excludes specific comments about quality of & life \\
Quality of life & Physian makes direct or indirect comments related to quality of life; excludes \\
& comments related to teamwork/partnership \\
Charting efficiency & Phsician makes direct or indirect comments about time spent on charting \\
Clinic operations & Physician refers to impact of clinic operations, including (but not limited to) late \\
& patients, no-shows, inefficient scheduling, and patient refusing scribe or student \\
participation & Physician comments about the EHR (EPIC) \\
EHR & Physician refers to impact on work done outside the exam room, including (but not \\
Non-patient-facing work & limited to) reviewing laboratory test results/radiology and responding to messages/ \\
& calls; excludes comments related to charting efficiency \\
Physician refers to impact on patient communication and connection, including (but & not limited to) eye contact, patient centeredness, attention to body language, and \\
Connection with patient & rapport; excludes comments related to patient satisfaction \\
& Physician refers to expanded role of scribes, including (but not limited to) assisting \\
with procedures, completing paperwork/forms, writing letters for school/work, \\
discussing health maintenance, and engaging in health coaching \\
Physician makes direct or indirect comments related to patient satisfaction; excludes \\
specific comments related to connecting with patients \\
Physician makes direct or indirect comments about charting style \\
Physian makes direct or indirect comments related to the quality or accuracy of \\
charting \\
Charting style
\end{tabular}

EHR, electronic health record; EPIC, Epic Systems Corp., Verona, WI.

themes emerged, which were further categorized under 4 domains: clinic operations, joy of practice, quality of care, and patient experience (Table 2).

The most frequently mentioned domain was clinic operations, which comprised 51.6\% (149 of 289) of the codes. The other 3 domains-joy of practice, quality of care, and patient experiencemade up $22.1 \%(\mathrm{n}=64), 16.3 \%(\mathrm{n}=47)$, and $10.0 \%(\mathrm{n}=29)$ of the codes, respectively (Figure 1). Interrater agreement was established between the 2 independent coders with a $\kappa$ value of 0.72 .

\section{Clinic Operations}

Themes under this domain included charting efficiency, clinic operations, EHR, extension of the scribe role, and non-patient-facing work. The majority of comments in this domain was positive or neutral $(66 \%$; 98 of 149); almost all the negative comments $(34 \%$; 51 of 149$)$ were related to operational inefficiencies (eg, "poorly booked clinic" or "patient refused the scribe") or dissatisfaction with the EHR that had nothing to do with scribes. Physicians expressed high satisfaction with efficiency of charting when a scribe was present, and appreciation when their scribes helped them with work beyond documentation support (eg, completing paperwork and forms, drafting letters, assisting with procedures).

\section{Joy of Practice}

Themes under this domain included teamwork/ partnership and quality of life. The vast majority of comments was positive or neutral (94\%; 60 of 64$)$; all the negative comments $(6 \% ; 4$ of 64$)$ were related to unfinished work that had to be done after hours, not related to the scribes.

\section{Quality of Care}

Themes under this domain included charting style and charting quality/accuracy. The majority of comments was positive or neutral $(60 \% ; 28$ of 47$)$. Most of the negative comments $(40 \% ; 19$ of 47$)$ described minor documentation errors made by scribes, nearly all of which occurred in the first several weeks of the study when the scribes and physicians just started working together. Later comments were unanimously positive.

\section{Patient Experience}

Themes under this domain included connection with patients and patient satisfaction; 100\% (29 of 
Table 2. Identified Themes and Domains with Representative Physician Comments

\begin{tabular}{|c|c|c|c|c|}
\hline \multirow[b]{2}{*}{ Themes, by Domain } & \multirow[b]{2}{*}{ Representative Physician Comments } & \multicolumn{3}{|c|}{ Comments, $\mathrm{n} / \mathrm{N}(\%)$} \\
\hline & & Positive & Neutral & Negative \\
\hline \multicolumn{5}{|l|}{ Domain 1: Clinic operations } \\
\hline Charting efficiency & $\begin{array}{l}\text { "She saved me easily } 15 \text { to } 20 \text { minutes which } \\
\text { I instead devoted to direct patient care } \\
\text { and inbox management. What a wonderful } \\
\text { asset!" } \\
\text { "This was one of those days where the } \\
\text { patient conversations were complex, } \\
\text { multifaceted, and difficult to follow. } \\
\text { Having [the scribe] there to record the } \\
\text { details so that when it came time for me } \\
\text { to finish my note I had to merely make } \\
\text { sense of/organize it was a true blessing!" }\end{array}$ & $33 / 43(76.7)$ & $2 / 43(4.7)$ & $8 / 43(18.6)$ \\
\hline Clinic operations & $\begin{array}{l}\text { "Poorly booked clinic, ran late." } \\
\text { "Last patient was someone I haven't seen in } \\
\text { a while so went over time because spent } \\
\text { extra with her. Appreciate that I feel a bit } \\
\text { less pressured in that context when alone } \\
\text { vs with a medical student or scribe } \\
\text { because it is only my time vs my and } \\
\text { someone else's." }\end{array}$ & $21 / 60(35.0)$ & $8 / 60(13.3)$ & $31 / 60(51.7)$ \\
\hline EHR & $\begin{array}{l}\text { "Sometimes challenging when we want to } \\
\text { view in the same part of the chart at the } \\
\text { same time. Leads to delays." }\end{array}$ & $0 / 8(0)$ & $1 / 8(12.5)$ & $7 / 8(87.5)$ \\
\hline Extension of scribe role & $\begin{array}{l}\text { "[The scribe's] help was invaluable! At the } \\
\text { end of the day she assisted me with an } \\
\text { IUD insertion, which freed up [the } \\
\text { medical assistant], which she was } \\
\text { incredibly grateful for! And [the scribe] } \\
\text { was also a huge help to me during the } \\
\text { procedure!" } \\
\text { "So glad [the scribe] was in clinic with me } \\
\text { today!! Had a particularly complex patient } \\
\text { encounter where she helped me gather } \\
\text { support and additional resources to best } \\
\text { care for the patient." }\end{array}$ & $28 / 28(100)$ & $0 / 28(0)$ & $0 / 28(0)$ \\
\hline Non-patient-facing work & $\begin{array}{l}\text { "One thing I have noticed lately is that } \\
\text { because I use my laptop to write notes } \\
\text { usually, when I have a scribe I do not do } \\
\text { as much in between patients in the case } \\
\text { that I only have a minute or two-seems } \\
\text { burdensome to log in to computer in that } \\
\text { context vs when I have my laptop I am } \\
\text { already logged in so can quickly review a } \\
\text { lab or message between patients even if } \\
\text { there is only a very short period of time } \\
\text { available." }\end{array}$ & $3 / 10(30.0)$ & $2 / 10(20.0)$ & $5 / 10(50.0)$ \\
\hline \multicolumn{5}{|l|}{ Domain 2: Joy of practice } \\
\hline Teamwork/partnership & $\begin{array}{l}\text { "So fun to have a 'partner in crime' and to } \\
\text { spend the day together!" } \\
\text { "It's also important to note that it is really } \\
\text { fun having [the scribe] to work with. She } \\
\text { is a friend now and a colleague." }\end{array}$ & $52 / 52(100)$ & $0 / 52(0)$ & $0 / 52(0)$ \\
\hline Quality of life & $\begin{array}{l}\text { "I just enter the day with a little a bit more } \\
\text { positivity knowing that I'm not going to } \\
\text { have this onslaught of all these charts to } \\
\text { catch up on at home." }\end{array}$ & $7 / 12(58.3)$ & $1 / 12(8.3)$ & $4 / 12(33.3)$ \\
\hline
\end{tabular}


Table 2. Continued

\begin{tabular}{|c|c|c|c|c|}
\hline \multirow[b]{2}{*}{ Themes, by Domain } & \multirow[b]{2}{*}{ Representative Physician Comments } & \multicolumn{3}{|c|}{ Comments, $\mathrm{n} / \mathrm{N}(\%)$} \\
\hline & & Positive & Neutral & Negative \\
\hline & $\begin{array}{l}\text { "I ran out of town right after clinic this } \\
\text { morning and it is so nice to know that my } \\
\text { notes are nearly done! I won't be able to } \\
\text { complete them before I leave, but am } \\
\text { happy and feel SO MUCH BETTER } \\
\text { knowing that there will be usable content } \\
\text { in the notes. ..." }\end{array}$ & & & \\
\hline \multicolumn{5}{|l|}{ Domain 3: Quality of care } \\
\hline Charting style & $\begin{array}{l}\text { ". . [ [the scribe] adapted to my A\&P style, } \\
\text { which I had been too shy to bring up to } \\
\text { her because I am so incredibly grateful for } \\
\text { her I don't want to appear 'nitpicky' but } \\
\text { she-completely without prompting-must } \\
\text { be reviewing my notes and made relevant } \\
\text { changes in anticipation of what my notes } \\
\text { end up looking like. AMAZING." }\end{array}$ & $3 / 5(60.0)$ & $0 / 5(0)$ & $2 / 5(40.0)$ \\
\hline \multirow[t]{2}{*}{ Charting quality/accuracy } & $\begin{array}{l}\text { "Today there were a few errors that are } \\
\text { completely understandable-confusion } \\
\text { about medication names and indications } \\
\text { and therefore written up incorrectly-in } \\
\text { the notes. It's a good practice to reflect on } \\
\text { my explanations and whether or not I am } \\
\text { speaking/communicating as clearly as I } \\
\text { can!" }\end{array}$ & $23 / 42(54.8)$ & $2 / 42(4.8)$ & $17 / 42(40.5)$ \\
\hline & $\begin{array}{l}\text { "[The scribe] completed the assessment and } \\
\text { plan portions of the note based on our } \\
\text { conversation and my conversation with the } \\
\text { patients and for most notes I literally only } \\
\text { changed a few words." }\end{array}$ & & & \\
\hline \multicolumn{5}{|l|}{ Domain 4: Patient experience } \\
\hline \multirow[t]{2}{*}{ Connection with patient } & $\begin{array}{l}\text { "I think I have a deeper level of intimacy with } \\
\text { patients when I'm not on the computer and } \\
\text { I'm just connecting with them. I'm using } \\
\text { my body language, I'm leaning in, and it's } \\
\text { just the two of us." }\end{array}$ & $20 / 21(95.2)$ & $1 / 21(4.8)$ & $0 / 0(0)$ \\
\hline & $\begin{array}{l}\text { "[The scribe] was so helpful with a teen with } \\
\text { mental health issues-I could focus } 100 \% \\
\text { on her and her mother with my eye contact } \\
\text { and body language without worry about } \\
\text { documentation. What a wonderful thing!" }\end{array}$ & & & \\
\hline \multirow[t]{2}{*}{ Patient satisfaction } & $\begin{array}{l}\text { "I had several patients comment today on } \\
\text { how they enjoyed visits with the scribes } \\
\text { much more than before I had a scribe." }\end{array}$ & $6 / 8(75.0)$ & $2 / 8(25.0)$ & $0 / 8(0)$ \\
\hline & $\begin{array}{l}\text { "[The scribe] also gave a sticker to my } \\
\text { grown-up patient who joked he wanted it } \\
\text { after his flu shot. It absolutely cracked him } \\
\text { up when she did it-what great rapport and } \\
\text { added value to the clinic experience." }\end{array}$ & & & \\
\hline
\end{tabular}

EHR, electronic health record; IUD, intrauterine device.

29) of the comments were positive or neutral. Physicians appreciated having a "deeper level of intimacy" with patients and being able to pay "more attention to body language" when they did not have to look at the computer. A few comments expressed ambivalence with scribes being in the room for sensitive discussions (eg, intimate partner violence), although they still ultimately wanted the scribe present during those difficult conversations so that they could focus entirely on the patient.

\section{Discussion}

To our best knowledge, this is the first study to use an ethnographic approach to determine how medical scribes affect the daily work of physicians, how 
Figure 1. Distribution of Coded Physician Comments in each domain $(n=289)$.

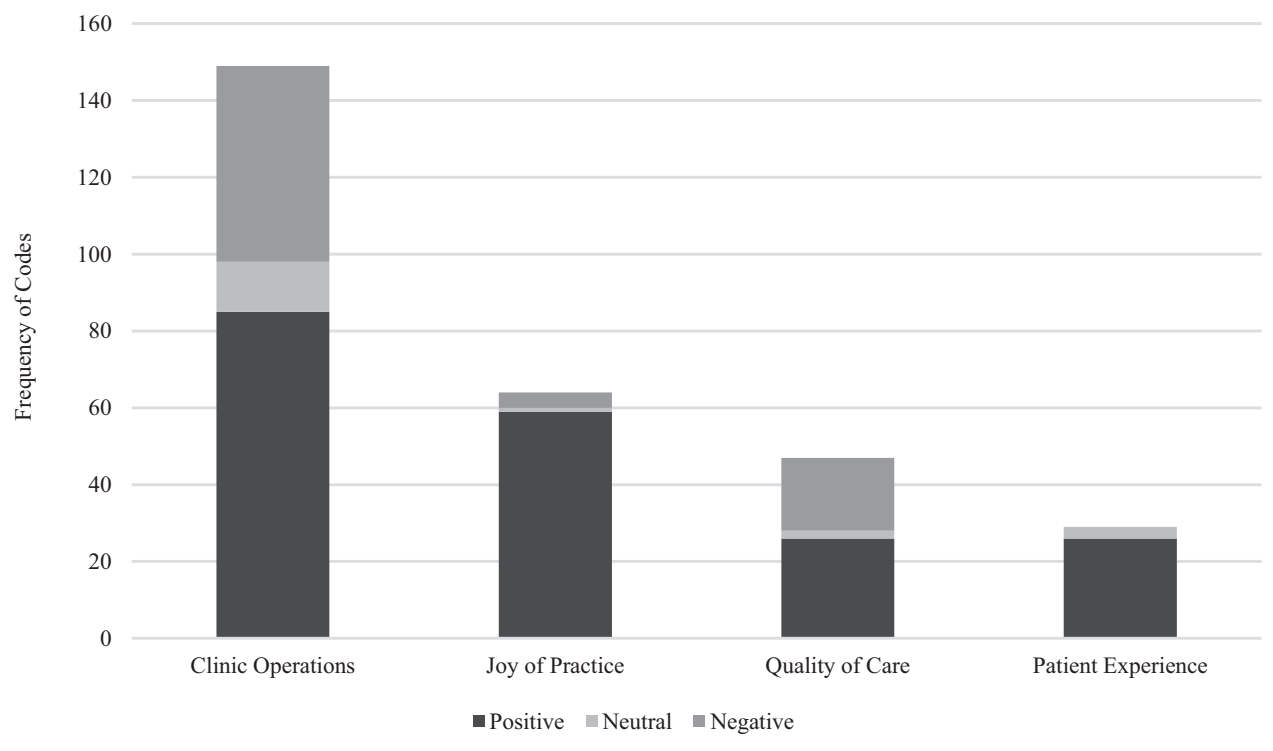

they fit into the dynamic interactions of physicians and patients, and how they change relationships and team structures in the primary care setting. Our study suggests that integrating scribes into a primary care clinic can produce positive outcomes that go beyond reducing clerical burden for physicians. Scribes may benefit patient experience, quality of care, clinic operations, and joy of practice. By identifying relevant themes and domains, we have set the groundwork for future, robust qualitative or mixed-methods studies on scribes in primary care.

\section{Clinic Operations}

The majority of physician comments were related to clinic operations. Consistent with previous research, physicians enthusiastically praised scribes for decreasing charting time. ${ }^{9-10,13}$ This led to time saved during clinic hours, thus allowing for the timely completion of other administrative tasks like answering patient calls, reviewing laboratory or radiology results, and responding to staff messages. Physicians appreciated this increased operational efficiency and expressed dismay when patients occasionally declined the scribe.

Physicians expressed gratitude when scribes extended themselves beyond documentation support to help complete paperwork and forms, draft letters, assist with procedures, talk with patients about overdue preventive health tests, and compile resources for families. These actions saved the phy- sicians time and relieved medical assistants from some clerical tasks so that they can focus on supporting physicians with the significant burden of in-basket management. ${ }^{16}$ This emerging triad partnership-physician, scribe, medical assistant-has the potential to improve physician wellness; studies have shown similar interventions that improve workflow, increase time for staff to complete tasks, and enhance teamwork can decrease physician burnout. ${ }^{17}$

One practical challenge identified was how to best navigate the EHR when both the provider and scribe are in the same section of the patient chart at the same time, a function that is not available in Epic and other EHRs.

\section{Joy of Practice}

Physicians described the partnership with their scribe as a "great psychological benefit" to their daily experience; having a partner with whom they could share difficult or emotionally charged encounters made them feel "less isolated" during the clinic day. Providers reported rediscovering a joy in practice as a result of working with scribes. They frequently had a healthier perspective going into work and a more relaxed attitude after clinic hours were over because they were less mentally burdened by the thought of charting. They expressed great satisfaction with having more time to spend with their families. 


\section{Quality of Care}

Physician comments related to quality of care focused on the completeness and accuracy of notes generated by scribes. Physicians reported high satisfaction with both the quality and accuracy of scribe documentation. They appreciated when the scribe took the time to learn and replicate their personal charting styles. Many physicians reported a decreased "sense of dread" when presented with a highly complex patient with multiple concerns, because they trusted their scribe to capture all the important details that they would have forgotten if they had to write the note themselves at the end of the day. This finding is consistent with a study demonstrating that scribed notes are of higher quality than physician-only notes. ${ }^{18}$

Some physicians expressed concerns about minor inaccuracies in the notes generated by scribes. This is of particular relevance in the context of OpenNotes, where patients are able to review their notes online. ${ }^{19}$

\section{Patient Experience}

Physicians generally praised the scribes as a way for them to bond with their patients, focus more on patients' nonverbal cues and the natural flow of conversations, and avoid excess attention on the computer screen during visits. One study demonstrated that primary care physicians spend as much as $36 \%$ of a clinic visit navigating the HER, which reduces eye contact and directs attention away from the actual patient. ${ }^{20}$ The experience of our physicians is consistent with that in a recent study involving scribes in the primary care setting, where physicians, scribes, and patients all described improved physician attention to patients when scribes were present. ${ }^{11}$

Providers reported that they could spend more time on interpersonal subtleties when a scribe was present in the examination room. In particular, certain communication challenges-for example, patient encounters performed in another language by a bilingual provider and conversations that involved complex family dynamics-were easier to navigate when the scribe was present, allowing the physician to focus on the conversation.

Providers also mentioned, however, that having a scribe present was not universally optimal, and that certain types of visits (eg, sensitive topics, intimate partner violence) might be better served with the provider and patient being in the room alone.

\section{Limitations}

Our study's biggest limitation is the small number of physicians and scribes, thereby restricting the generalizability of these results. However, the longitudinal nature of the study and our ethnographic approach allowed for a deeper dive into rich qualitative data. Another limitation is that because entries were optional, each physician's perspective is not equally represented in the final data set; 2 of the 4 physicians contributed the majority of the comments. Last, these results represent only the perspectives of physicians, not patients or scribes. More research is needed to better understand the impact of scribes on other stakeholders in our health systems.

\section{Conclusions}

In the era of team-based care, scribes are the newest member of the care team, yet relatively little is known about their impact on physicians and practices. Our study shows that integrating scribes into a primary care setting can benefit clinic operations, joy of practice, quality of care, and patient experience. These positive outcomes go beyond reducing charting burden and may all play a role in preventing physician burnout.

Some of our findings on the impact of scribes are well established (eg, scribes decrease charting time, make physicians happier, allow better nonverbal communication with patients); others are less obvious but perhaps more interesting (eg, evolution of scribe role beyond documentation to include medical assistant tasks, implications of scribed notes in the context of OpenNotes). Here we used an ethnographic approach to identify the relevant themes and domains to set the groundwork for future research.

The question of how primary care practices can make the economic argument for scribes remains unanswered. Thus far, much of the focus has been on paying for scribes using revenue generated by additional visits afforded by increased efficiency. If primary care physicians want to argue for scribes in their practices, we believe that the justification should expand beyond just higher visit volumes to include potential benefits in clinic operations, quality of care, patient experience, and joy of practice. 
The authors thank Sang-ick Chang, MD, MPH, associate dean for primary care, and Juno Vega, RN, clinic manager for Stanford Family Medicine, for their support of the scribe program. They also thank Sylvia Bereknyei Merrell, DrPH, for her advice on data analyses.

To see this article online, please go to: bttp://jabfm.org/content/ 31/1/49.full.

\section{References}

1. Dyrbye LN, Shanafelt TD. Physician burnout: a potential threat to successful health care reform. JAMA 2011;305:2009-10.

2. Shanafelt TD, Hasan O, Dyrbye LN, et al. Changes in burnout and satisfaction with work-life balance in physicians and the general US working population between 2011 and 2014. Mayo Clin Proc 2015;90: $1600-13$.

3. Gottschalk A, Flocke SA. Time spent in face-to-face patient care and work outside the examination room. Ann Fam Med 2005;3:488-93.

4. Gilchrist V, McCord G, Schrop SL, et al. Physician activities during time out of the examination room. Ann Fam Med 2005;3:494-9.

5. Chen MA, Hollenberg JP, Michelen W, Peterson JC, Casalino LP. Patient care outside of office visits: a primary care physician time study. J Gen Intern Med 2011;26:58-63.

6. Sinsky C, Colligan L, Li L, et al. Allocation of physician time in ambulatory practice: a time and motion study in 4 specialties. Ann Intern Med 2016; 165:753-60.

7. Gellert GA, Ramirez R, Webster SL. The rise of the medical scribe industry: implications for the advancement of electronic health records. JAMA 2015; 313:1315-6.

8. Campbell LL, Case D, Crocker JE, et al. Using medical scribes in a physician practice. J AHIMA 2012;83:64-9.

9. Shultz CG, Holmstrom HL. The use of medical scribes in health care settings: a systematic review and future directions. J Am Board Fam Med 2015; 28:371-81.
10. Heaton HA, Castaneda-Guarderas A, Trotter ER, Erwin PJ, Bellolio MF. Effect of scribes on patient throughput, revenue, and patient and provider satisfaction: a systematic review and meta-analysis. Am J Emerg Med 2016;34:2018-28.

11. Yan C, Rose S, Rothberg MB, Mercer MB, Goodman K, Misra-Hebert AD. Physician, scribe, and patient perspectives on clinical scribes in primary care. J Gen Intern Med 2016;31:990-5.

12. Imdieke BH, Martel ML. Integration of medical scribes in the primary care setting: improving satisfaction. J Ambul Care Manage 2017;40:17-25.

13. Gidwani R, Nguyen C, Kofoed A, et al. Impact of scribes on physician satisfaction, patient satisfaction, and charting efficiency: a randomized controlled trial. Ann Fam Med 2017;15:427-33.

14. Goodson L, Vassar M. An overview of ethnography in healthcare and medical education research. J Educ Eval Health Prof 2011;8:4.

15. Ng S, Lingard L, Kennedy TJ. Qualitative research in medical education: methodologies and methods. In: Swanwick T, ed. Understanding medical education: evidence, theory and practice. 2nd ed. West Sussex, UK: John Wiley \& Sons; 2014: 371-84.

16. Murphy DR, Meyer AN, Russo E, et al. The burden of inbox notifications in commercial electronic health records. JAMA Intern Med 2016;176:559-60.

17. Linzer M, Poplau S, Grossman E, et al. A cluster randomized trial of interventions to improve work conditions and clinician burnout in primary care: results from the Healthy Work Place (HWP) Study. J Gen Intern Med 2015;30:1105-11.

18. Misra-Hebert AD, Amah L, Rabovsky A, et al. Medical scribes: how do their notes stack up? J Fam Pract 2016;65:155-9.

19. Delbanco T, Walker J, Darer JD, et al. Open notes: doctors and patients signing on. Ann Intern Med 2010;153:121-5.

20. Farber NJ, Liu L, Chen Y, et al. EHR use and patient satisfaction: what we learned. J Fam Pract 2015;64:687-96. 